\title{
The effect of span length to height ratio of reinforced concrete slabs on pressure-impulse diagram with multiple failure modes under blast loading
}

\author{
W. Wang, D. Zhang, F. Lu, S.C. Wang, and F. Tang \\ Institute of Technique Physics, College of Science, National University of Defense Technology, Changsha, \\ Hunan 410073, P.R. China
}

\begin{abstract}
In this paper, two loosely coupled single degree of freedom (SDOF) systems are used to generate pressure-impulse diagrams (P-I) with the flexural and direct shear responses of one-way reinforced concrete slabs subjected to blast loading. The effect of span length to height ratio in P-I diagrams is investigated. The numerical calculation results indicate that a slab tends to fail in a direct shear mode if the blast load amplitude is high but of short duration. It tends to fail in flexural failure mode if load amplitude is relatively low and duration is relatively long. And the failure of the slab might be a combination of shear and flexural damage in the dynamic loading region. Based on numerical results, different failure modes are got with different the span length to height ratio on the P-I diagrams. Results indicate that there is only shear failure mode in the P-I diagrams when $\mathrm{L} / \mathrm{h}<10.9$. When $\mathrm{L} / \mathrm{h}>24.89$, there are two damage mode in the P-I diagrams with flexure failure mode and flexure-shear failure mode. When $10.9<\mathrm{L} / \mathrm{h}<24.89$, there are three damage modes in the P-I diagrams: shear failure mode, flexure failure mode and flexure-shear failure mode.
\end{abstract}

\section{Introduction}

Pressure-impulse (P-I) diagram method was first used to assess damage of structural elements and buildings in World War II [1]. In protective design, P-I diagrams have been extensively used for approximate damage assessments of structural components when subjected to blast loading. According to the P-I diagram of a specific structure or structural element, a certain load with the peak pressure and impulse above the critical curve will result in the damage of the structures, vice versa, the structure is safe if the peak pressure and impulse combination is located below the curve.

However, the SDOF system oversimplifies a structural element and neglects the influence of shear force, which subsequently leads to the ignorance of shear failure. It has been observed that shear failure may occur when the ratio of span-to-height of the structural element is relatively small or when the detonation is very close to the structures $[2,3]$. And the P-I diagrams generated by the current approaches may not give reliable prediction of structure component damage because of the following reasons: the SDOF analysis is incapable of capturing a spatially and temporally varying distribution of blast loading, cannot allow for variations of mechanical properties of the cross-section along the member, cannot simultaneously accommodate shear and flexural deformations, can only address strain rate effects indirectly, and may produce very conservative answers.

In the present study, extending the models derived by Krauthammer et al. [4] and Low [5], a P-I diagram method of one-way reinforced concrete slab based on the two loosely coupled SDOF systems incorporating the effects of the strain rate effect caused by rapid load application is developed. Two loosely coupled SDOF systems are used to model the direct shear and flexural failure modes. The influence of span length to height ratio on the P-I diagram are investigated by the simply SDOF methods. Based on numerical results, different failure modes are got with different the span length to height ratio on the P-I diagrams.

\section{Criteria for bending and shear failure}

According to TM5-1300 [6] and UFC3-340-02 [7], in the design of a structure to resist the blast loading, the design method consists of the determination of the total internal force, i.e. the resistance of the structure required to limit calculated deflections of the individual members and the structure as a whole under the external force (blast loading), to within prescribed maximum values.

The shear deformation at the element supports can be expressed by:

$$
y_{s}=D I F \cdot \delta \cdot \gamma \cdot e
$$

where shear sliding $y_{s}$ is a cumulative quantity over the shear band, DIF is the dynamic increase factor of material, $\delta$ is a material parameter calculated from experiment result, $\gamma$ is the average shear strain and $e$ is the half-width of the shear band for a beam and is a function of the depth of the beam $h$. Normally $\delta$ varies in 0.6-0.866 for different materials. In present study, $\delta$ is fixed at 0.8 . The threshold shear strain for reinforced concrete members is shown in Table 1.

The support rotation defined by the ratio of the calculated peak deflection to half the span length is employed as the criterion of bending failure $[6,8]$. The maximum bending deformation of the element is defined as

$$
y_{m}=D I F \cdot L \cdot \tan \theta
$$

where $L$ is half length of the element, and $\theta$ is the support rotation.

This criterion as shown in Table 1 corresponds to the experimental phenomena and theoretical derivation for 
Table 1. Empirical bending and shear damage criteria $[6,8]$.

\begin{tabular}{|l|c|c|c|c|}
\hline $\begin{array}{c}\text { Type of } \\
\text { failure }\end{array}$ & Criteria & $\begin{array}{c}\text { Light } \\
\text { damage }\end{array}$ & $\begin{array}{c}\text { Moderate } \\
\text { damage }\end{array}$ & $\begin{array}{c}\text { Severe } \\
\text { damage }\end{array}$ \\
\hline Bend & $\begin{array}{c}\text { Support } \\
\text { rotation } \theta\end{array}$ & $2^{\circ}$ & $5^{\circ}$ & $12^{\circ}$ \\
\hline Shear & Shear strain $\gamma$ & $0.5 \%$ & $1 \%$ & $1.5 \%$ \\
\hline
\end{tabular}

reinforced concrete members. For simplification of both far design range and close-in design range, DIF for direct shear stress is fixed at 1.10, and DIF for bending stress is fixed at 1.20 .

\section{Equivalent SDOF systems}

In this paper two coupled SDOF systems with tri-linear resistance functions are used to represent the shear and flexural response mode of the slab [4]. The first system is used for modeling the flexural response at the point of maximum displacement along the span of the structure (i. e. at midspan as the loading and structure are symmetrical), and the second is for monitoring the direct shear response at the support.

\subsection{Flexural response SDOF and resistance}

The SDOF system for modeling the flexural response is based on Biggs [9], where the deflected shape of the structure is assumed to be the same as that resulting from the static application of the dynamic load. The equivalent mass and stiffness parameters are derived based on the mass density, Young's modulus, moment inertia, span length and boundary condition of the slab, as well as the deflection shape of the slab under distributed static load. More details can be found in Biggs [9]. The accuracy of using a SDOF system to model the slab response to blast loads was proven by Krauthammer and his coauthors [3]. The simplification for flexural response has been widely accepted and recommended in Protective design manuals $[6,7]$.

Upon transforming the structural slab into its equivalent flexural SDOF system, the governing differential equation of motion is presented as follows [4]:

$$
\ddot{x}(t)+2 \xi \omega^{\prime} \dot{x}(t)+\frac{R}{M_{e}}=\frac{P_{e}(t)}{M_{e}}
$$

in which $x(t), \dot{x}(t)$, and $\ddot{x}(t)$ are the flexural displacement, velocity, and acceleration, respectively, $M_{e}$ is the equivalent mass of the system, $R$ is the flexural dynamic resistance function, $\omega^{\prime}$ the flexural damped natural circular frequency, $\xi$ the flexural damping ratio, and $P_{e}(t)$ is the equivalent forcing function. The nonlinear equation is solved numerically using the Newmark $\beta$ method. The time step is $0.1 \%$ of smallest value of natural periods and positive loading duration, which is compared to US Army approach.

The flexural resistance function $(R-x)$ of concrete structures under blast load is highly nonlinear. In this

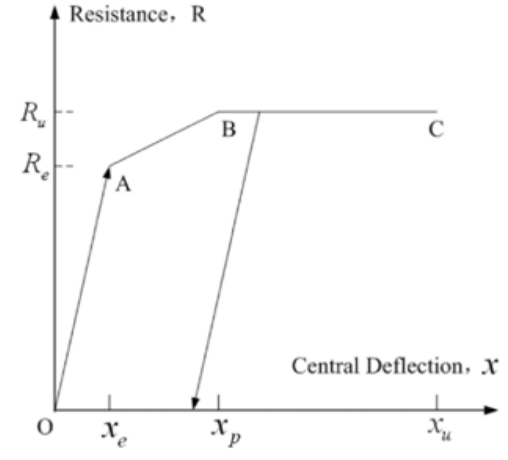

Fig. 1. Flexural resistance model.

paper the function of structures is assumed to be tri-linear resistance functions for one-way fixed support slab and the slope of the unloading path is the same as that of loading path [10], as shown in Fig. 1. More details can be found in the protective design manuals [10].

\subsection{Shear response SDOF and resistance}

The shear SDOF system is used to model the direct shear response of the slab. Since the direct shear mode is expected to occur within a very short duration after the initiation of the explosive loading, the structure would not have any significant deformation at that time, and because the failure plane occurs very near to the support, the phenomenon is very much like a sudden collapse of the entire slab. This implies that the shape function of the structure can be taken as unity with negligible deflection. The transformation factors for the shear mass, direct shear stiffness as well as the loading are taken as unity too [4].

The nonlinear differential equation of motion for the equivalent SDOF system was given by Krauthammer [4]:

$$
\ddot{y}(t)+2 \xi_{s} \omega_{s}^{\prime} \dot{y}(t)+\frac{R_{s}}{M_{s}}=\frac{V(t)}{M_{s}}
$$

where $y(t), \dot{y}(t)$, and $\ddot{y}(t)$ are the direct shear slip, velocity and acceleration, respectively, $M_{s}$ is the equivalent shear mass, $R_{S}$ is the dynamic resistance function for direct shear response, $\omega_{s}^{\prime}$ is the natural circular frequency for direct shear response, $\xi_{s}$ is the direct shear damping ratio, and $V(t)$ is the dynamic shear force (or reaction) which can be computed by the forcing function $P(t)$ and the dynamic resistance function $R(t)$ in flexure SDOF systems as shown in Biggs [9]. This nonlinear equation for direct shear is also solved numerically using the Newmark $\beta$ method and the time step is $0.1 \%$ of smallest value of natural periods and positive loading duration.

The direct shear resistance function of RC structures is not well developed and thus is more empirical. The model used, as shown in Fig. 2, is based originally on Krauthammer et al's work [3]. It consists of five straight line segments, namely the elastic response segment OA, hardening segment $\mathrm{AB}$, plastic flow segment $\mathrm{BC}$, softening segment $\mathrm{CD}$ and final yielding segment DE. The model was developed by modifying a few existing shear stressslip models. In actual application, Krauthammer et al. [11] 
Table 2. Standard values of the slab adopted in analysis.

\begin{tabular}{|l|c|c|c|c|c|}
\hline $\begin{array}{l}\text { Dimension } \\
(\mathrm{m})\end{array}$ & $\begin{array}{c}\text { Reinforcement } \\
\text { ratio (\%) }\end{array}$ & $\begin{array}{c}\text { Concrete Compressive } \\
\text { strength }(\mathrm{MPa})\end{array}$ & $\begin{array}{c}\text { Concrete tensile } \\
\text { strength }(\mathrm{MPa})\end{array}$ & $\begin{array}{c}\text { Steel yield } \\
\text { strength MPa }\end{array}$ & $\begin{array}{c}\text { Concrete cover } \\
\text { thickness mm }\end{array}$ \\
\hline 210.1 & 1.34 & 39.5 & 8.2 & 600 & 10 \\
\hline
\end{tabular}

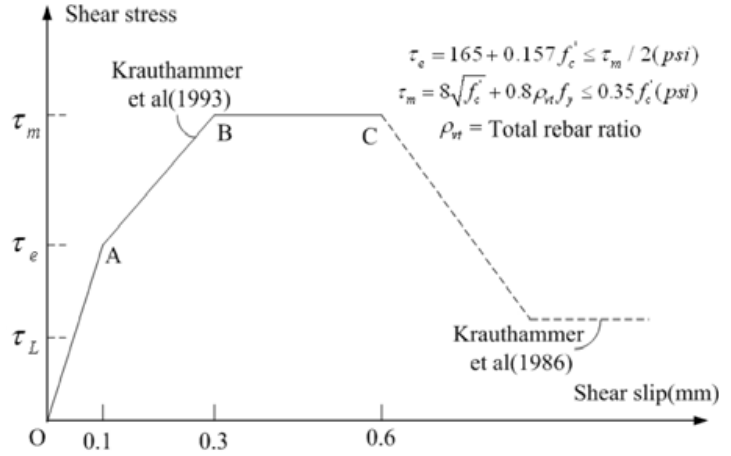

Fig. 2. Direct shear resistance model.

did not consider the softening region, and the model used was a tri-linear one. In the present study, the tri-linear model is used in the dynamic analysis. The yielding and the maximum allowable shear slip are taken as $0.1 \mathrm{~mm}$ and $0.6 \mathrm{~mm}$, respectively as shown in Fig. 2. An enhancement factor of 2 is multiplied to the direct shear strength, as done in Krauthammer et al. [3] to account for the rapid loading rate. This factor is indeed obtained from tests by Chung [12].

\section{P-I diagram of the two failure modes}

The P-I diagram has the advantage to evaluate conveniently the structural safety against blast load. Consider a case study of a fixed normal reinforced concrete slab (NRC) with of dimensions $2 \times 1 \times 0.1 \mathrm{~m}^{3}$ with $1.34 \%$ tension reinforcement and nominal top reinforcement. Detailed information of the slab used is given in Table 2. The blast load is on the assumption of uniformly distributed and pressure time history on a slab is simplified to a triangular shape as

$$
\begin{gathered}
P(t)=\left\{\begin{array}{cc}
P_{\max }\left(1-t / t_{d}\right), & 0<t<t_{d} \\
0 & t>t_{d}
\end{array},\right. \\
I=\int_{0}^{t_{d}} P(t) d t
\end{gathered}
$$

where $P_{\max }$ is the peak reflected pressure of the blast wave, $t_{d}$ is the duration for triangular loading simplification.

Fig. 3 shows two light damage failure P-I typical curves of the Slab, respectively, for bending and shear failure. As can be seen, there are four regions denoted, respectively, as A, B, C, and D in the Fig, each of which represents one particular situation for the slab. Region $\mathrm{D}$ represents that under the given pressure and impulse, neither shear failure nor bending failure will occur. Region $\mathrm{B}$ assumes that by the pressure and impulse given in this region, the slab will only experience bending failure.

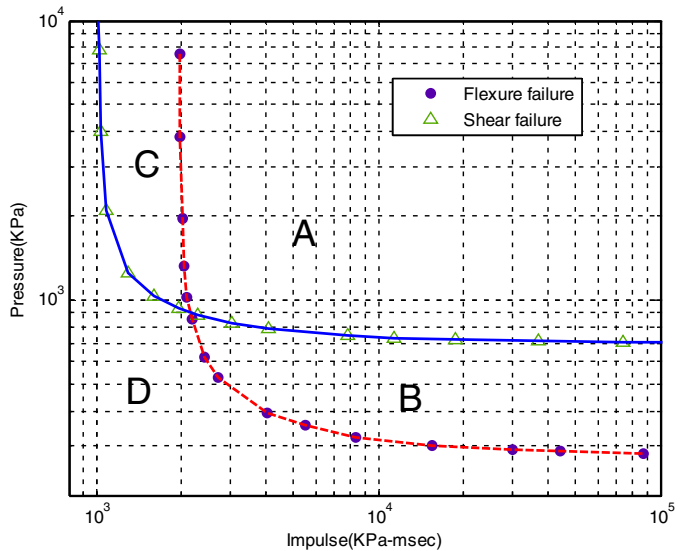

Fig. 3. P-I diagram for flexure and shear failure mode (light damage).

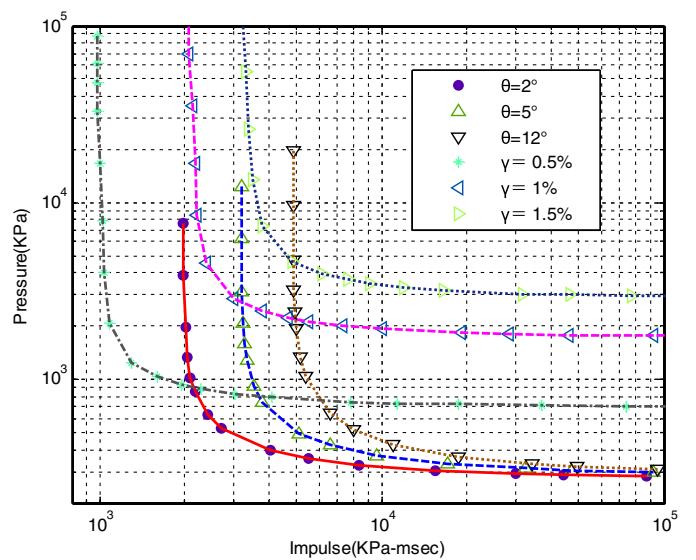

Fig. 4. P-I diagram for different flexure and shear damage levels.

Shear failure will not occur because the pressure and impulse of the pulse load locates below the P-I curve which corresponds to a critical shear slide of the slab. In region $\mathrm{C}$, however, the slab will suffer shear failure only. In region A, both shear failure and bending failure will occur for the slab.

With different damage levels as define before, the P-I diagrams are generated using SDOF systems with different failure modes for the slab as shown in Fig. 4. The PI diagram contains six critical P-I curves with different damage levels and modes: three flexure damage curves with $\theta$ equal to $2^{0}, 5^{0}$ and $12^{0}$ respectively, and three shear damage curves with $\gamma$ equal to $0.5 \%, 1 \%$ and $1.5 \%$ respectively. It is inclined to be damaged by shear impulsive loading region and by flexural mode in the quasistatic region for different damage levels. It is seen that based on the P-I diagram generated using the two loosed coupled SDOF systems, not only the safety of the slab can 


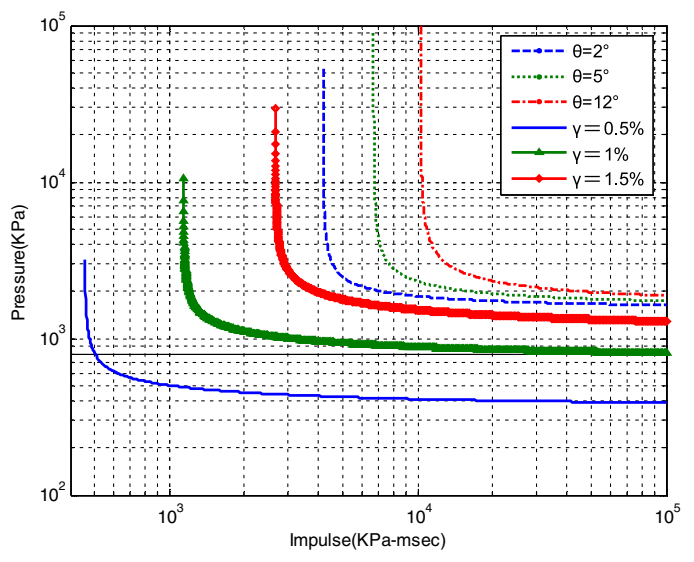

Fig. 5. Comparison of P-I curves for RC slabs with span length equals to $1 \mathrm{~m}$.

be evaluated, but also different failure modes of the slab can be identified.

\section{P-I diagram with different span length}

A series of simulations is run for slabs with different span lengths to investigate the effects of span length on the RC slab P-I diagram. It should be noted that in all the cases, the two shorter sides of the slabs are fixed supported, and the other two sides are free. The P-I diagrams shown in Fig. 5Fig. 7 of three RC slabs with different span lengths, i.e., 1000,1800 and $4000 \mathrm{~mm}$ are derived using the proposed method. The width of the slabs is all $800 \mathrm{~mm}$ and the thickness of the slab is $150 \mathrm{~mm}$, the concrete strength and the reinforcement ratio is the same with the RC slab1.

From Fig. 5 one can see that when the span length is equal to $1 \mathrm{~m}$, all the shear failure curves below the flexure failure curves. The slab will be failure in shear mode in all regions. While the span length is $1.8 \mathrm{~m}$ as shown in Fig. 6, the slab is inclined to be damaged by shear in impulsive loading region and is likely damaged by flexural mode in quasi-static region as shown in section 4 . When the span length is increase to $4 \mathrm{~m}$, all the flexure failure curves below the shear failure curves as shown in Fig. 7. The slab will be failure in flexure mode in all regions. This means that the slab is prone to be failure by flexure mode in both impulse and quasi-static region.

Table 3 shows the pressure asymptotes and impulsive asymptotes of the P-I curves, from which one can see that both the pressure asymptote and impulsive asymptote of flexure failure decrease with the span length. However, the pressure asymptote and impulsive asymptote of shear failure are opposite. This result is consistent with the fact that when the slab is longer, it is likely to be damaged by flexure failure mode, and when the slab is shorter it is incline to be damaged by shear failure mode.

This is demonstrated in the variation of both pressure asymptotes and impulse asymptotes of light damage P-I curve, corresponding to d different span length to height ratio $(\mathrm{L} / \mathrm{h})$ of the slab in Fig. 8. It is found that when $\mathrm{L} / \mathrm{h}<$ 10.9 , both pressure asymptotes and impulse asymptotes of shear failure curve below the flexure failure curve, and

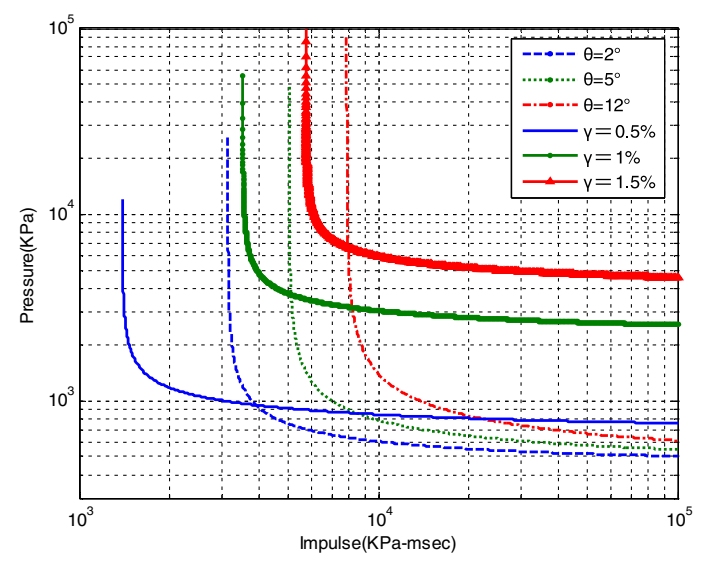

Fig. 6. Comparison of P-I curves for RC slabs with span length equals to $1.8 \mathrm{~m}$.

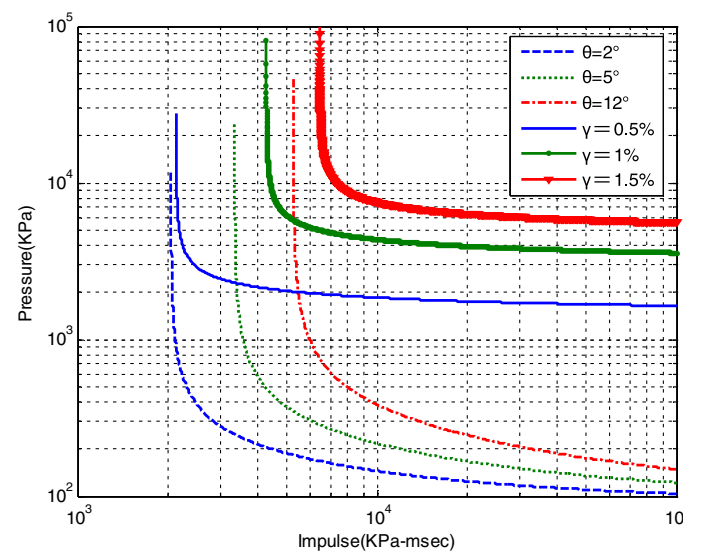

Fig. 7. Comparison of P-I curves for RC slabs with span length equals to $4 \mathrm{~m}$.

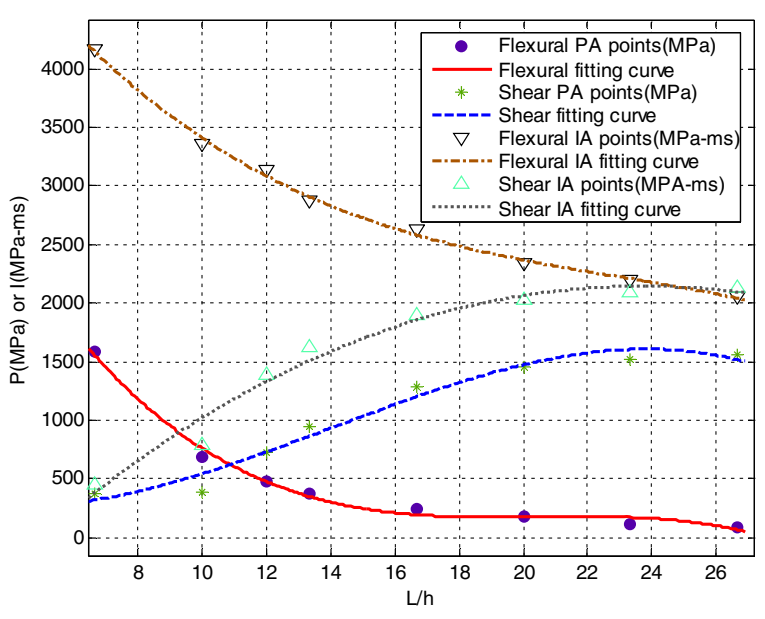

Fig. 8. Variation in asymptotes with different $\mathrm{L} / \mathrm{h}$ ratio.

there only exists shear failure of the slab as shown in Fig. 5. When $\mathrm{L} / \mathrm{h}>24.89$, both pressure asymptotes and impulse asymptotes of flexure failure curve below the shear failure curve, the slab is prone to be damaged in flexure failure mode as shown in Fig. 7. And when $10.9<\mathrm{L} / \mathrm{h}<24.89$, the pressure asymptotes of shear failure mode is higher than the flexure failure mode, but the impulse asymptotes 
Table 3. Effect of span length on pressure and impulsive asymptotes.

\begin{tabular}{|l|c|c|c|c|c|c|c|}
\hline Type of failure & Span length $(\mathrm{mm})$ & $\mathrm{P}_{01}(\mathrm{KPa})$ & $\mathrm{I}_{01}(\mathrm{KPa}-\mathrm{ms})$ & $\mathrm{P}_{02}(\mathrm{KPa})$ & $\mathrm{I}_{02}(\mathrm{KPa}-\mathrm{ms})$ & $\mathrm{P}_{03}(\mathrm{KPa})$ & $\mathrm{I}_{03}(\mathrm{KPa}-\mathrm{ms})$ \\
\hline \multirow{3}{*}{ bend } & 1000 & 1584 & 4162 & 1647 & 6646 & 1716 & 10278 \\
\cline { 2 - 9 } & 1800 & 478 & 3134 & 498 & 5020 & 517 & 7830 \\
\cline { 2 - 9 } & 4000 & 92 & 2050 & 98 & 3342 & 101 & 5257 \\
\hline \multirow{3}{*}{ shear } & 1000 & 381 & 457 & 774 & 1140 & 1196 & 2675 \\
\cline { 2 - 9 } & 1800 & 721 & 1391 & 2383 & 3521 & 4200 & 5699 \\
\cline { 2 - 8 } & 4000 & 1557 & 2130 & 3315 & 4270 & 5115 & 6433 \\
\hline
\end{tabular}

is opposite. In other words, there are three damage modes in the P-I diagram as shown in Fig. 6.

\section{Conclusions}

In this paper, a simplified method to obtain P-I diagrams with multiple failure modes of one-way reinforced concrete slab is developed by using two loosely coupled SDOF models. It is shown that based on the generated P-I diagram, not only the safety of the slab can be evaluated, but also different failure modes of the slab can be identified. The numerical calculation results indicate that a slab tends to fail in a direct shear mode if the blast load amplitude is high but of short duration. It tends to fail in flexural failure mode if load amplitude is relatively low and duration is relatively long. And the failure of the slab might be a combination of shear and flexural damage in the dynamic loading region. Using the two loosely coupled SDOF models, further study is also carried out to study the effect span length to height ratio on the P-I diagram of the $\mathrm{RC}$ slabs. Results indicate that there is only shear failure mode in the P-I diagrams when $\mathrm{L} / \mathrm{h}<10.9$. When $\mathrm{L} / \mathrm{h}>$ 24.89 , there are two damage mode in the P-I diagrams with flexure failure mode and flexure-shear failure mode. When $10.9<\mathrm{L} / \mathrm{h}<24.89$, there are three damage modes in the P-I diagrams: shear failure mode, flexure failure mode and flexure-shear failure mode.

\section{References}

1. Smith PD, Hetherington JG. Blast and ballistic loading of structures. Oxford: Butterworth-Heinemann; 1994. p. 1-336.
2. Karthaus W, Leussink JW. Dynamic loading: more than just a dynamic load factor. Proceedings of Symposium on the Interaction of Non-Nuclear Munitions With Structures, Colorado, USA, 1983:151-154.

3. Krauthammer T, Bazeos N, Holmquist TJ. Modified SDOF analysis of RC box-type structures. J Struct Eng ASCE 1986;112(4):726-44.

4. Krauthammer T, Shahriar S, Shanaa HM. Response of reinforced concrete elements to severe impulsive loads. J Struct Eng 1990, 116(4):1061-79.

5. Low HY, Hao H. Reliability analysis of direct shear and flexural failure modes of RC slabs under explosive loading. Eng Struct, 2002, 24, 189-98.

6. Army TM 5-1300, Structures to resist the effects of accidental explosions, US Department of the Army. 1990.

7. UFC 3-340-02 (TM5-1300), Structures to resist the effects of accidental explosions, 2008.

8. Krauthammer, T. Blast mitigation technologies: developments and numerical considerations for behavior assessment and design. In: Proceedings of International Conference on Structures Under Shock and Impact, SUSI, Thessaloniki, Greece, June 24-26, 1998. p. 1-10.

9. Biggs JM. Introduction to Structural Dynamics. McGraw-Hill, 1964.

10. PDC-TR 06-01 Rev 1, Methodology manual for the Single degree of freedom blast effects design spreadsheets, US Army Corps of Engineers. 2008.

11. Krauthammer T, Assadi-Lamouki A, Shanaa HM. Analysis of impulsive loaded reinforced concrete structural elements. I: Theory Comput Struct 1993;48(5):851-60.

12. Chung HW. Shear strength of concrete joints under dynamic loads. J Concrete Soc 1978,12(3):27-9 